\title{
The Lives and Deaths of Jobs: Technical Interdependence and Survival in a Job Structure
}

\author{
Sharique Hasan \\ Stanford University \\ sharique@stanford.edu
}

\author{
John-Paul Ferguson \\ Stanford University \\ jpferg@stanford.edu
}

\author{
Rembrand Koning \\ Stanford University \\ rkoning@stanford.edu
}

Please do not cite or circulate without permission

\begin{abstract}
Prior work has considered the properties of individual jobs that make them more or less likely to survive in organizations. Yet little research examines how a job's position within a larger job structure affects its life chances and thus the evolution of the larger job structure over time. In this article, we explore the impact of technical interdependence on the dynamics of job structures. We argue that jobs that are more enmeshed in a job structure through these interdependencies are more likely to survive. We test our theory on a quarter-century of personnel and job-description data for the non-academic staff of one of Americas largest public universities. Our results provide support for our key hypotheses: jobs that are more enmeshed in clusters of technical interdependence are less likely to die. At the same time, being part of such a cluster means that a job is more vulnerable if its neighbors disappear. And the "protection" of technical interdependence is contingent: it does not hold in the face of strategic change or other organizational restructurings. We offer implications of our analyses for research in organizational performance, careers, and labor markets.
\end{abstract}

\section{Introduction}

Organization theory invokes the concept of job structures to explain many processes, from the shapes of workers' careers, to organizational learning, to patterns of technological change. Job structures, broadly conceived, are the grouping of tasks into specific jobs and the tying together of those jobs as part of a division of labor within the organization. The fact that jobs are linked is fundamental to all theories of organizations as systems (Scott \& Davis 2006). Furthermore, most theories of macro-organizational behavior rely on "meso-level" mechanisms that invoke tasks, routines, careers, and status hierarchies, all of which relate to one another through a job structure. Organizational ecology for example presumes that routines produce inertia that limit organizational adaptability (Hannan \& Freeman 1984); and routines are hard to change precisely because of the interdependence among jobs. Both contingency theory (Thompson 1967) and neoinstitutional 
approaches (Meyer \& Rowan 1977) presume that organizations have and can protect a technical core of jobs while redesigning or eliminating other jobs to satisfy external actors; this presumes there is variation in how vulnerable to change different jobs in the organization are. A basic question that cuts across many parts of organization theory, then, is how jobs structures change and evolve over time.

Despite the importance of this question, the theoretical elaboration of and empirical research into the causes of change in job structures has often been indirect. Woodward's (1984) classic work on technological contingency hypothesized why an organization might have one job structure or another, but was silent on why any particular job was likely to persist or disappear. The long tradition of strategic design (Thompson 1967, Lawrence \& Lorsch 1967) offers prescriptive advice on how to group tasks into jobs but rarely investigates whether and how organizations change their job structures over time to conform to these prescriptions. Case studies of occupations and professions within organizations detail work reorganizations and suggest mechanisms for why some jobs disappear and others do not (Trist \& Bamforth 1951, Barley 1986, Smith 1990, Autor, Levy \& Murnane 2002, Bechky 2003b), but subsequent work has rarely tried to generalize those mechanisms to other contexts. And while some research has explicitly focused on the "life-chances" of jobs in organizations over time (Baron \& Bielby 1986, Miner 1987, Miner 1991, Barnett \& Miner 1992), these studies have downplayed or ignored the fact that these jobs are linked together in a structure. All of these approaches have illuminated certain aspects of job change. Yet we do not have studies that directly examine the general effects of location within a job structure on the life-chances of a particular job over time.

In this article, we undertake such an examination. We explore how the technical interdependencies among jobs affect their life chances. We use the term "technical interdependence" in the sense used by Trist \& Bamforth (1951), Mintzberg (1990), and others, where "technology" broadly refers to the work performed by the organization and "interdependence" refers to the level of cooperation and coordination required among organizational incumbents to perform that work. We hypothesize that, all else equal, jobs that are more technically interdependent with other jobs are less likely to be eliminated. Our hypotheses derive from the premise that jobs that are more enmeshed in such technical relationships, that are more core and less peripheral to the overall job structure, will be more likely to survive. At the same time, technical interdependence should protect jobs less when 
entire clusters of jobs are being removed, for the same reason.

We exploit a new set of data, comprising some 1,400 unique non-academic jobs occupied by more than 90,000 personnel in one of the nation's largest public universities over nearly a quarter century. A critical aspect of these data is that we have detailed descriptions for each job. We know each position's primary duties and responsibilities, necessary qualifications, and reporting relationships. Mining this detailed textual information enables us to calculate direct measures of task overlap and coordination, rather than relying on proxies like personnel movements. In addition to technical relationships, we control for the individual characteristics of the jobs, such as their educational requirements, the age and feminization of their workforce, and so on. The sheer variety of jobs in this internal labor market makes our findings more generalizable to other settings; and the longitudinal structure of the data lets us include a rich set of fixed effects to control for many sources of unobserved heterogeneity.

We find that jobs that are more technically interdependent with other jobs are indeed less likely to die. We also find that this relationship is subject to two contingencies, both of which relate to whether changes are being made to whatever cluster the job is part of. First, the death of jobs with which the focal job is interdependent make the focal job more likely to die. Second, technical interdependence does not protect jobs when the organizational sub-units in which they are performed are being restructured.

Our findings make contributions to several parts of organization theory. First, by developing a more concrete method for measuring task overlap, we offer a way to study technical interdependence that can be generalized to other organizations. Second, the types of interdependence within job structures about which we theorize have implications both for organizational performance and survival and also for individual outcomes like careers and occupational segregation. Finally, the methodological approach that we develop here, which combines detailed personnel records with a large corpus of textual data, could be extended to explore other processes that have been documented within organizations but that have been difficult for researchers heretofore to systematically study. 


\section{Technical interdependence and job survival}

Within organizations, change is experienced as changes to jobs (Cohen 2012). Speaking analytically, there are three ways that a job can be changed. First, the content of the job can be altered, as when computerization introduces new and different tasks. Second, the relationships between jobs can be altered, as when a reporting hierarchy is shuffled. Third, the job can be eliminated - the job can die. Herein, we theorize about the technical relationships that protect a job from dying.

A job is understood as distinct from the incumbents who perform it or the tasks they perform. Rather, a job is the bundling of a discrete group of tasks to be performed by an individual. In creating such bundles, organizations also typically specify the qualifications that an individual must have to do the job (Cohen 2013). A job can die, therefore, if the organization stops performing the job's tasks, but more commonly job death is the removal of a specific bundling of tasks, even if some or all of the tasks are still performed (Miner \& Estler 1985). For example, a firm might have a director of sales and marketing; as the firm grows, it appoints separate directors of sales and of marketing, killing the original job while preserving all of the tasks. Nor need job death require firing the old job's incumbent. Job death is fundamentally about the disappearance of positions within job structures.

Prior research uses such a conceptualization of job death. Work on union job control, for example, problematizes which tasks should be bundled together, as the resulting job change is fundamental to the extent of managerial control (Chamberlain 1948, Noble 1984, Barker 1993). Theories of competition among professions (Abbott 1988, Halpern 1992, Leicht \& Fennell 1997) similarly define turnover among jobs in terms of the allocation or reallocation of tasks to different jurisdictional bundles. Ethnographic studies of work reorganization often operationalize precisely such reallocations of tasks as the death of old jobs and the birth of new ones (Bechky 2003b, Huising \& Silbey 2011). New jobs can involve new tasks, and indeed new technologies or new lines of work are often the genesis of such reorganizations (Trist \& Bamforth 1951, Barley 1986). Nonetheless the carving of new jobs from an existing body of organizational tasks is well understood to have implications for the status, identities, and prospects of job incumbents (Barley 1990, Baron 2004, Boeker \& Wiltbank 2005).

Quantitative studies of job change also rely heavily on this conception of jobs as positions within 
organizations, often because information on the task content of specific jobs has been unavailable. Thus for example Baron \& Bielby (1986) focus on the proliferation of job titles, assuming that change in the population of formal organizational positions is of interest, even absent information about the underlying task structure. Similarly Baron, Davis-Blake \& Bielby (1986) focus on the existence of formal promotion ladders between positions separately from the actual movements of incumbents between jobs. That jobs are formal positions designed and defined independently of the incumbents who occupy them aligns with organizational theory about bureaucracy (Weber 1968, DiPrete 1989) and most descriptions of internal labor markets (Doeringer \& Piore 1971, Osterman 1987). In practice, of course, incumbents can shape the jobs into which they move, which means that job death can result from idiosyncratic pressures applied by existing employees as well as from changes in organizational needs or goals (Miner 1987, Miner 1990).

Overall, though, very few studies of job change consider the disappearance of positions as an important dependent variable. Those that do overwhelmingly focus on the effects of either job content or incumbent characteristics - self-contained properties of the job. Yet it is also important to consider the relationships between jobs in an organization: "To tease out the microprocesses of job death, future studies...should [model] the interdependence of jobs and people" (Miner (1991, p. 782); see also Cohen (2012)). We think that technical relationships are particularly important to consider because organizational theory has long suggested that being enmeshed in many technical interdependencies should stabilize a job, but few studies have directly measured technical interdependence or its effects.

Technical interdependence should protect jobs by raising the cost and complexity for the organization to eliminate that job. Formal organizations perform a multitude of tasks. A job can be understood as collecting some subset of those tasks together and assigning a single person to perform them. A firm that produces recycled rubber mats to line the beds of pick-up trucks, for example, must sort used tires and feed them into shredders; mold and cure the mats; inspect the quality of the finished mats and the efficiency of the production process; install and maintain the physical plant; sell and distribute the mats; keep financial accounting and control of its operations; and so on. A fundamental component of job design has always been deciding which tasks should be grouped together in or separated between jobs (Blau 1963, Montgomery 1979, Noble 1984, Bechky 2003b).

If we could see through the jobs in an organization and visualize an underlying web of tasks, we 
would see that tasks vary in how interconnected they are with one another. Some tasks produce the inputs for other tasks; some tasks use or combine the outputs of other tasks; some tasks always have to happen at the same time; and so on. Because jobs are bundles of tasks, it follows that they will vary in how many task-related connections they will have to other jobs. The technical relationship of jobs through their interdependent tasks is the core of our conception of organizations as complex systems (Appelbaum, Bailey, Berg \& Kalleberg 2000).

Existing theory about organizational routines dovetails with our thinking about task interdependence. Organizations develop routines to make complex operations faster and more predictable (Nelson \& Winter 1982). Durable routines involve a division of labor and coordination among multiple individuals (Cohen \& Bacdayan 1994). Organizations that have better-established routines out-perform other organizations, in part because they spend less effort and resources on monitoring and disputes over who should do what work. Yet at the same time, routines are a powerful source of inertia within organizations, because the complex coordination implied by well-developed routines makes changing any one job harder without upsetting the larger routine (Hannan \& Freeman 1984). Partly as a result, prior work has theorized that organizations with more routinized operations are more vulnerable to rapidly changing environments, because the interdependence of tasks within routines makes adaptation more difficult (Sørensen 2002). We think that a measure like ours, which builds on the overlap of tasks across job descriptions, is a useful way to make this thinking about routines more concrete and testable.

The differing task interdependence of jobs has implications for job change. The circumstances under which jobs die are varied:

$[D]$ esignated funding sources disappear; the incumbent departs and the job is left unfilled (permanently, or on an experimental basis); the job ends during planned reorganization; and the job is terminated in reaction to unexpected threats or shocks to the organization. Jobs are thus terminated, either individually or in large groups, either slowly or in dramatic waves during reorganization or mass layoffs (Miner 1990, p. 199).

The motivation of organizational decision-makers is similarly varied. In some circumstances, as during changes in strategy or reorganization, managers may choose to pro-actively "kill off" a position. In others, as in the wake of retirements or economic downturns, the same managers may let a job die by not hiring replacements for departing incumbents. We bracket most of these managerial motivations, for the following reason: in each case, the manager who has been driven to 
decide, for whatever cause, whether to eliminate a job must think through the impact that changing that one job will have on other jobs in the organization. If a job is not very interdependent with others, then all else equal, eliminating it will upset very little elsewhere. On the other hand, eliminating a job with many interdependencies will also require modifying or at least making sure there are not undue disruptions to those other jobs. Consider two examples, one in healthcare, the other in construction, both drawn from the data examined here.

Therapy clinics have multiple job titles, many of which perform many of the same tasks. For example, a "Physical Therapist" may focus on teaching patients regular exercises to strengthen muscles after surgery or an injury. A "Physical Therapy Clinical Specialist" has a more diagnostic role, designing programs of physical therapy and evaluating whether a patient has recovered enough to return to regular duties; but the clinical specialist must also regularly coach patients through the same exercises that the physical therapist teaches. Meanwhile, an "Occupational Therapy Clinical Specialist" will devise procedures and programs that tailor patients' physical and psychological treatment to the specifics of their jobs, but they also have to be able to assess patients' competence at the types of exercises taught by physical therapists, in order to know whether the patient is ready and capable to handle more job-specific activities. Furthermore, both Physical Therapy Clinical Specialists and Occupational Therapy Clinical Specialists often supervise some of the same lower-level therapy personnel. These jobs perform many overlapping tasks. In this example, several jobs all contribute to the larger project of patient rehabilitation. Because they work on a similar project, the wording used to describe the tasks performed by each of these jobs tends to overlap. The need for each of these jobs to complete that project means that eliminating any one of these jobs is complicated by overlapping responsibilities. The complexity of such overlaps increases with the number of relationships involved. This leads us to hypothesize that, at the margin, jobs that have greater task overlap with other jobs are more likely to survive.

Hypothesis 1 Jobs that have greater task overlap with other jobs will be less likely to die.

We should note that the null hypothesis is compelling here. If a job performs tasks that are performed by many other jobs, then it is conceivable that eliminating the job might be easier. There are more people in the organization who are familiar with some elements of the job, and 
could presumably take over the bulk of its tasks were it eliminated. ${ }^{1}$ In stating our hypothesis, we presume that the fact that the task is being done by several jobs tells us something important about the underlying level of interdependence needed to carry out the larger project, and that this interdependence will dominate any redundancy in the descriptions; but ultimately this is an empirical question.

Turning to the second example: erecting a new building requires framers, electricians, and plasterers, among others. Electricians usually cannot run wiring and conduit through the walls and floors of a building before framers have put the walls and floors into place. Similarly, plasterers cannot (or at least should not) hang drywall before the electrical work is installed. While there is a great deal of sequential interdependence among them, these jobs do not perform many overlapping tasks - the specific nature of their work is quite different. Management of the interdependencies of this work is rarely handled by the trades themselves. Rather, contractors working on the building project oversee coordination. There is clearly interdependence between contractors and the building trades, but it takes a different form from the task overlap seen in therapy work. The contractor's interdependence arises because it must coordinate the performance of multiple jobs, even though it has little task overlap with any one of them. For example, the contractor must manage the schedules of when each trade is on site, but the contractor does no framing, wiring, or plastering. The contractor must ensure compliance with building codes, order and receive materials, and liaise between architects and other contractors. In this second example, the contractor contributes to a larger project, but does so through explicit rather than implicit coordination. Their role is necessary, but the tasks they perform look quite different from those performed by any one of the jobs whose work they coordinate. This implies that the interdependence inherent in such jobs will be poorly measured by task overlap. Interdependence for these jobs inheres in the explicit act of coordination: liaising, consulting, interacting, and so on.

Arguably, jobs that involve explicit coordination might be no more or less likely to survive than the jobs they coordinate. Coordination can be thought of as just another function. A product manager fills an important role, but not necessarily one that is more important than the engineer or designer in making the product. In this sense active coordination might not be valued any more or less than other types of tasks. Yet we think that the relationship of the coordinating task to the job

\footnotetext{
${ }^{1}$ We thank an anonymous reviewer for this point.
} 
structure itself is consequential, perhaps more so than other tasks. Other tasks can be outsourced, recombined in different jobs, or dropped because of technological changes; thus jobs that perform these tasks can disappear. For a coordinating job to become unnecessary, though, the entire division of labor that it has previously helped manage must disappear. We are not arguing that, for example, outsourcing a coordinating job is impossible; the prevalence of external contractors in areas like construction attests that this is not so. Rather, the threshold for eliminating jobs that involve explicit coordination should be higher than for other jobs. We say this because organizations rarely hire external parties to coordinate multiple jobs performed by existing employees. Instead it is usually after several such jobs have been outsourced that outsourcing a coordinator job begins to make sense. At the margin, the likelihood of the coordinating job's dying should therefore be lower.

Hypothesis 2 Jobs that involve more explicit task coordination will be less likely to die.

This point about outsourcing coordinating roles after the jobs that they coordinate have been outsourced, as well as the parallel with routines, suggests an additional hypothesis. Technical interdependence makes a job more likely to survive, but it also implies that when a job is eliminated, those jobs that are related to it are more likely to also be eliminated. This would happen for at least two reasons. First, if we imagine a cluster of jobs that are all highly interdependent, a hypothetical manager would find it more convenient or tractable to redesign the entire cluster than to renegotiate all of the tasks and interdependencies within it. Second and similarly, even were the manager to eliminate one of those highly related jobs without thinking in advance about the impact on the others, eventually the other jobs would suffer and require redesign or elimination themselves. Such cascading effects (Hannan, Pólos \& Carroll 2003) would mean that when a job is eliminated, the jobs most technically interdependent with it will have a greater chance of dying.

Hypothesis 3 Deaths of jobs with which the focal job is technically interdependent will increase the focal job's risk of death.

It is worth underlining that most prior work on routines has stressed their ambiguous implications for the survival of organizations. At the level of the job, we have no such ambiguity. More interdependence implies more durable jobs. Yet we fully recognize that such durability is not necessarily good for the organization as a whole. That is, we make no efficiency claims about long-lasting jobs. It is easy to imagine organizations that fail because their members find it too difficult to dis- 
entangle the connections between different jobs and thus do not change jobs that "should" change. But organizational inertia does imply job survival, and in that sense is good for the job itself.

Thus far, we have theorized about the effects of technical interdependence on the decision to eliminate individual jobs. We have discussed a hypothetical manager considering the relative difficulty of eliminating one job as opposed to another one. In practice, though, many decisions about job change or restructuring do not happen this way. Rather, organizations make decisions at a higher level and then decisions have implications for jobs. Thus a firm might change its product strategy, with cascading implications for multiple jobs in different product lines. A university might open or close an institute, affecting large clusters of jobs at one go. A company might decide that it has to lay off large numbers of employees, and use the situation as a chance to prune some jobs. A shared feature of such decisions is that there is less job-by-job evaluation happening; instead the organization is choosing among clusters of jobs. If we want to accurately portray technical interdependence's effect on job survival, we should also consider such circumstances.

To do so, it is important to note that, while such large organizational shifts almost always involve eliminating personnel, they do not necessarily involve eliminating jobs. To continue with the example of a firm and its product lines: many jobs - director of marketing, director of sales, industrial designer, industrial engineer and so on - are repeated across such lines. Closing one line would not eliminate these positions within the company, as other incumbents would fill them elsewhere. This nonetheless suggests a way to incorporate such organizational restructuring into our theory. In general, we might expect that, as more sub-units in which a job is found are closed, the job's likelihood of death should increase.

Hypothesis 4 Closure of the organizational sub-units in which the focal job is found will increase the job's likelihood of death.

How should such closures interact with technical interdependence? We have argued both that being part of a cluster of interdependent jobs should be a protection and that being part of a cluster links a job's life-chances to its neighbors'. When decisions about job elimination are being made at the level of the cluster - that is, when organizations are making strategic or structural decisions that have implications for groups of jobs - we theorize that technical interdependence should protect jobs less. Specifically, in those cases where clusters of jobs are being eliminated-where sub-units 
are being closed - the technical interdependence of a job within that cluster should provide it little protection. We hypothesize this in terms of interactions between hypothesis 4 and hypotheses 1 and 2.

Hypothesis 5 The protection given jobs by task overlap will be reduced as closures of sub-units in which the job is found increase.

Hypothesis 6 The protection given jobs by task coordination will be reduced as closures of subunits in which the job is found increase.

We can now summarize how technical interdependence between jobs affects job survival. We begin with the premise that the job structure is a useful way to think about change within organizations, and therefore focus on how that structure affects the survival chances of individual jobs. We conceive of a job structure as consisting of technical relations of task overlap and coordination among jobs. Jobs that are more enmeshed in such relationships are more likely to be protected than jobs that are not. At the same time, interdependence yokes jobs to one another, such that decisions about their survival are themselves interdependent. Thus killing of closely related jobs, or closing sub-units where the job is performed, should counteract any benefits of technical interdependence.

The data requirements for testing these hypotheses are considerable (Miner 1991). At a minimum, such tests require data on many jobs over a long time span. Those data should include detailed substantive descriptions of each job's duties and qualifications, so that we can construct measures of technical interdependence for each job. An organization that performs many different functions is preferable to a more specialized one, both to give us more jobs and to increase the generalizeability of the results. The organization should also have multiple sub-units and experience reorganizations. We have such data available in job and employment data from a major public American university, to which we now turn.

\section{Empirical setting: A "Multiversity" labor market}

The setting for our study is the non-academic internal labor market of the University of Michigan, for decades one of the largest universities in the United States. The university has a large and strikingly diverse internal labor market. Through Freedom of Information Act requests, we acquired human-resource data on university employees from 1979 through 2009 as well as the school's formal, 
standardized job descriptions for every position within its internal labor market. We stress that the theoretical mechanisms that we posit do not rely on the idiosyncrasies of a university. Our mechanisms draw on theories that were derived in a variety of organizational settings, including forprofit firms (Nelson \& Winter 1982, Morrill 1991, Bechky 2003a), government agencies (Blau 1963, Baron \& Bielby 1986, Strang \& Baron 1990), educational institutions (Miner 1987, Miner 1991) and more. These theories are about general organizational processes, such as routines or the division of labor, which organization theorists have long assumed operate upon most organizational forms. Clearly, the most straightforward mapping of results obtained in this context would be to other large, established, hierarchical organizations that perform many functions, and where many different types of jobs exist. We would expect our propositions and findings to apply less well by contrast to smaller, entrepreneurial firms where jobs' task content is more flexible, where jobs have been less separated from the incumbents who perform them, and where rapid organizational growth and change have made it hard to pause and codify tasks in formal job descriptions. The part of our setting that poses the largest problems of generalizeability is the professoriat; for this among other reasons we exclude academic jobs from our analysis.

The human-resource data consist of person-year observations for every employee at the university, starting in January 1979 and running through December 2009. We have each employee's full name, job title, salary, departmental affiliation and full- versus part-time status. From employee names we were able to impute gender for 98.8 percent of the employees using existing gender disambiguation databases (For the remaining 1.2 percent, we randomly assigned gender based on the university-wide distribution). The complete personnel data consists of 809,259 person-year observations of 111,982 unique employees.

Michigan made major revisions to its human-resources management system in 2005 and changed many job titles. Lest we attribute job death to such reforms, we limit our analysis to persons and jobs that appear in the data before 2005. Limiting the HR data to the quarter century between 1979 and 2004 reduces the total person-year observations to 628,860 and unique jobholders to 90,156 . There were 17,827 employees in 1979 and 33,244 in 2004; on average, the university grew by 639 persons every year.

The job-description data come primarily from paper descriptions in the archives of Michigan's human resources department. Descriptions were available for 5,131 unique job titles that we re- 
duced to 3,587 unique jobs. We combined job titles if the titles were only slightly different (e.g., using "Mgr" rather than "Manager") and had the same description. The vast majority (more than 98 percent) of job descriptions were issued after 1966. The descriptions have information about the job's duties and responsibilities and the desired qualifications for the jobholder. The descriptions also list the job's pay grade, the description's issue date, whether another job supervises the described job and whether it supervises another job. For example, the job "Nurse Consultant" was required to "[p]rovide leadership in various area administrative committees including patient education, joint practices, information/communication, computerized inpatient census system" as well as "[d]evelop objectives, coordinate, prepare presentations, present in-services and evaluate educational programs." Furthermore, the job description indicated that the jobholder was supervised by the position "Director or Assistant Director of Nursing" and exercised supervision over "Clinical nurses and support staff." The online appendix reproduces some sample job descriptions.

We linked the personnel data to the job description data. We excluded all professorial and teaching staff from our employee data, as the university does not have formal descriptions for positions such as Professor. This reduced the number of person-year observations in our data to 502,961 and the number of unique jobs in the employee data to 2,541 . We found job descriptions for 93.5 percent of the person-year observations in the personnel data. (Of the remaining 6.5 percent, more than 97 percent are the academic jobs.)

We reduced the person-year observations to job-year observations. This reduction results in 2,541 jobs and 36,530 job-years. Our empirical strategy is to use event-history analysis to model when and whether job death occurs. In such models, it is critical for obtaining accurate parameter estimates that observations not be "left-censored" (Singer \& Willett 2003). Our job-description data go back to 1964. Many of the jobs in these data were created before 1964, and are therefore left-censored. Furthermore, our personnel data, from which we construct many control variables, only go back to 1979. To deal with both of these data limitations and to obtain unbiased estimates, we analyze all jobs that were created after 1979. This allows us to trace all jobs in our sample from their birth to their death or right-censoring in 2004. The final sample for the analyses therefore contains 1,405 unique jobs and 15,604 job-years. 


\section{Measures}

Our analytical strategy is to estimate how differences in technical interdependence across jobs affect whether and when jobs die. For hypotheses 1, 2, and 3, we focus on between-job comparisons, for two reasons. First, we have theorized about why organizational decision-makers would choose to eliminate one job rather than another. Second, while job descriptions, and our resulting measures of technical interdependence, do vary slightly over time, the overwhelming share of variance in jobs' technical interdependence exists between jobs. Hypothesis 4 is a pooled comparison, reflecting how sub-unit closures can affect different jobs at varying times in their lifespans. Hypotheses 5 and 6 , which examine how sub-unit closure moderates the effects of technical interdependence, are in turn between-jobs comparisons.

\section{Dependent variable: Job death}

Our key outcome variable is a dichotomous indicator of whether a job dies in a given year. We define a job as being "dead" when the formal position is no longer occupied in any future period. For example, the job "Apprentice Sign Painter," which first appears in 1990, has no employees in 1993 or any following year through 2004. Thus we define the Apprentice Sign Painter job as having died at the end of 1992. Of the 1,405 jobs that were created between 1979 and 2003, 595 died.

When coding job deaths, we were careful to use the personnel data to double-check that the job was not simply renamed. We could see this happen when for example a job lost all of its incumbent employees between one year and the next and all of the incumbents were present the next year in a common job with a different title. Thus our measure specifically excludes the waves of specious deaths produced for example when the term "supervisor" passes out of fashion in favor of "coordinator," or when draftsmen are re-christened as draftspersons. Figure 1 shows the number of job deaths by year. Deaths increase over time, but this is an artifact of our sampling frame (jobs created after 1979).

[Figure 1 about here.] 


\section{Independent variables}

We have described two different ways to operationalize technical interdependence. One is task overlap, the other is task coordination. We hypothesize that both these types of technical interdependencies will have the same effect on job survival. The challenge is to devise separate measures for each.

In order to calculate the task overlap of jobs theorized in hypothesis 1, we use the text from the job descriptions' "duties and responsibilities" sections. We pre-process the text descriptions by converting all words into lowercase and stripping endings, punctuation, and non-alphabetic characters (Hopkins \& King 2010). Next, we create an annual corpus of duties and responsibilities texts from jobs that were alive in a given year (i.e., had at least one incumbent in the personnel records). Using this corpus, we model each description as a "bag of words" that ignores word order. Each job description in year $t$ is represented by a $1 \times W$ vector, where $W$ is the number of unique words in that year's corpus. For job $i$ in year $t$, the value of each element of the vector is set to $f_{w, d t} \times f_{w, i t}^{-1}$, where $f_{w, d t}$ is the frequency of word $w$ in year $t$ 's corpus and $f_{w, i t}^{-1}$ is the inverse frequency of word $w$ in job $i$ 's duties and responsibilities section. (We take the natural log of $f_{w, i t}^{-1}$ because it gives the resulting variable a more normal distribution.) These corpus-frequency-versus-inversejob-frequency weightings let us put more weight on words that are particular to a job description; a word that appears often in a description is given more weight but is then downweighted if the word appears in many other descriptions. ${ }^{2}$ To ensure that extremely rare words do not bias the task overlap measure, we exclude from the corpus matrix any words that occur fewer than three times.

We stack these vectors of job descriptions into an $N \times W$ job-word matrix. We then produce a symmetric $N \times N$ job matrix wherein cell $(i, j)$ records the cosine similarity between vectors $(i,$.$) and (j,$.$) in the job-word matrix. Cosine similarity measures the overlap of the task content$

\footnotetext{
${ }^{2}$ Intuitively, the corpus frequency versus inverse document frequency measure captures the idea that commonly used words, like "work," provide little information within a corpus of job descriptions but that rarer words, such as "fundraise," provide greater information about what the specific job does and thus which other jobs it is likely related to. We calculate the weighted document-term matrix by first counting the term frequency within a job description, normalized by the number of words in the description. We then weight this count by the inverse document frequency, which is the logarithm of the total number of descriptions in the corpus divided by the number of descriptions which have the word. For example, if the word "analyze" occurs five times in a 25-word description and the corpus contains 1,000 job descriptions of which 500 contain the word "analyze," then the weight would be $\frac{5}{25} \times \ln \left(\frac{1000}{500}\right)=0.06$. If only 20 job descriptions in the corpus used the word "analyze," then the weight would be much greater: $\frac{5}{25} \times \ln \left(\frac{1000}{20}\right)=0.34$.
} 
of different jobs. It is bounded between zero and one, where one represents complete overlap. Repeating this process for each year in our data produces twenty-five job matrices. At this point, we have $N-1$ pairwise measures of task overlap for each job in each year. Our goal is to have a measure of how much a job overlaps with its neighbors; therefore for each job we sum the five largest elements of its vector in the job matrix. This procedure ultimately yields a measure of how much a job's tasks overlap with those of the five jobs in the university that are most related to it. This score has a distribution that is approximately normal, with a mean of 2.85 and a standard deviation of 1.04. (Table 2 presents summary statistics for all variables used in our analyses.)

To give some concrete examples of how our measure of task overlap works, table 1 shows the five most-overlapping jobs to focal jobs at different points in the score's distribution, to demonstrate how the components of the score vary. "Locksmith," at the tenth percentile, is a largely self-contained job; the most-overlapping job, that of "Supervisor, University Key Systems," only has a cosine similarity of 0.223, and even the fifth most-overlapping job, that of "Heavy Equipment Mechanic," is obviously an unrelated line of work. By comparison, the "Supervisor, Cyclotron Facilities" job, at the twenty-fifth percentile, has at least two jobs with which it shares a substantial number of tasks; and "Physical Therapy Clinical Specialist," at the ninetieth percentile, has at least five related jobs.

[Table 1 about here.]

An intuitive way to conceive of task coordination as theorized in hypothesis 2 is to consider jobs whose descriptions include words that emphasize explicit coordination. Job descriptions that have more such words in them should entail more coordination with other jobs (Reitzig \& Sorenson (2013) adopt a similar word-counting and -classifying approach to measure the innovative content of crowd-sourced ideas). To build such a measure, we scanned through the full corpus of words built from the job-description data. We focused on words that were used more than three times and that were not stop words ("a," "and," "of," etc.). We went through this list manually to build our list of coordinating words, because we wanted to include possible mis-spellings that could result from digitizing the original printed job descriptions. Some such words, like "apprentice" and "manage," obviously have multiple meanings beyond task coordination. We therefore created a smaller list of words that focuses on the variants of "collaborate," "coordinate," "interact," "liaise," and "team." 
Both complete word lists are reproduced in the online appendix. We use the shorter list of explicitcoordination words in our analyses here; using the longer list produces substantively similar results.

Our two measures of technical interdependence are correlated, but by no means perfectly so. To more formally validate that our overlap measure operationalizes a separate theoretical construct from the coordination measure, we performed an experiment wherein we presented raters with 1,000 randomly paired jobs (without titles) and asked them to rate on a seven-point scale both how much the jobs' tasks overlapped and how much the jobs generally relied on one another. (Details of this experiment are available in the online appendix.) That experiment revealed that raters' assessment of the jobs' task overlap was most strongly correlated with the cosine similarity scores that our algorithm produced (and which the raters never saw). This increases our confidence that cosine similarity does measure task overlap among these jobs.

To test hypothesis 3 , which proposes that jobs are more likely to die when jobs with which they share technical interdependencies die, we calculate for each job the number of their five nearest neighbors on our task-similarity measure that died in the previous year. Different windows produce substantively similar results.

To test hypothesis 4, which proposed that jobs are more likely to die when sub-units in which they are found are closed, we first cleaned up the organizational information in the personnel data. Each employee's records list the sub-unit of the university in which they work in a given year. These might be academic departments, separate centers or institutes (such as the Center for Population Research or the Institute for Political Studies), medical facilities, physical-maintenance plants, and so on. Based on these personnel records, we coded when a sub-unit closed (visible by the disappearance of any employees in that sub-unit in later years). For each job-year, we counted the number of unique sub-units where the job was performed that closed. To test hypotheses 5 and 6 , we interact this count of sub-unit closings with our measures of task overlap and task coordination.

\section{Control variables}

Our theoretical interest in this study is how the technical interdependence among jobs affects their survival. However, we know from prior research that "node-level" characteristics of jobs affect their death rates as well. We therefore control for such job-specific features.

First, we control for the size of the job, in terms of the number of incumbents in a given year. 
We also include fixed effects for the year the job was created and the current time period in all models unless otherwise noted.

Second, we control for job characteristics that are aggregates of the characteristics of the jobs' incumbents. Jobs that are created with a single individual in mind are more likely to die, because a job's "overspecializing" in one type of person's qualifications and desires makes it harder to secure new incumbents should that person leave (Miner 1987). We control for whether the job is a singleton, i.e., has only one incumbent in any given year. We know that the feminization of a job can reduce its pay, status and chance of survival (Baron \& Bielby 1985, Cohen \& Broschak 2014). We create an indicator of feminization that is set to 1 in a given year if the job's incumbents are more than 80 percent female. Jobs that require greater educational requirements have tended to be more stable (Osterman 1987); accordingly, we control for whether a job requires a bachelors degree. Unionized positions are typically more stable because of work rules and seniority provisions. While these data do not have direct indicators of union status, we can get a close approximation by including the FLSA non-exempt status of the jobs. Union jobs are overwhelmingly paid hourly rather than on salary, thus not exempt from the Fair Labor Standards Act; and in Michigan in this time period, hourly jobs are disproportionately unionized. We similarly control for whether jobs are full-time or part-time, calculated based on the average full-time-equivalent compensation of the job's incumbents in a given year.

We presume that higher-status jobs are both better paid and more likely to survive. We therefore include the log mean salary of a job's incumbents in each year (in 2011 dollars). We control for the mean tenure of a job's incumbents in the job but do make any directional predictions about its effect. To help capture status, we measure whether a job has hierarchical relationships - that is, whether it is linked to other jobs via formal supervisory relations-based on text in the job descriptions. Fifty-one percent of the jobs in our sample have such relationships.

A potential concern with our analysis is that ultimately what we pick up with our task-overlap measure is not the effect of task overlap per se but rather the fact that different types of jobs are simply more "important" to a university in some unmeasured sense, and that task overlap varies systematically with that importance. In other words, it would be useful to control for the substantive type of job being done, as well as the job's task overlap. Controlling for each different job would make it impossible to identify any model; therefore we need a way to cluster the jobs 
into a smaller number of job topics, for which we can then include fixed effects. To do this, we used latent Dirichlet allocation, which is an algorithmic method for uncovering latent topics in a large corpus of data (Blei, Ng \& Jordan 2003). First, the analyst specifies the number of desired topics. Second, probability values are assigned to each word, indicating how likely the word is to belong to each topic. Finally, each document is assigned a probability of belonging to each topic, based on the underlying probabilities of its constituent words. We experimented with different numbers of topics and found that the algorithm produced no substantial changes to the corpus classification if we raised the number of topics above ten. We therefore fit the LDA model using ten topics and the variational EM method as implemented in the topicmodels package in $\mathrm{R}$. We fit the model using the text corpuses pooled across all years and discard any term that appears fewer than five times. We decided to pool the descriptions in this procedure to capture "timeless" latent categories of jobs within the university, which, overall, should remain stable even if individual jobs within a topic area are born and die over time. The LDA procedure produces for each job ten values indicating the probabilities that a job belongs to each topic. We dichotomize each variable such that a job belongs to a topic if its probability is greater than 0.2 . The online appendix presents the ten topics with representative words and jobs for each.

In robustness checks described below, we test whether our results are sensitive to larger forces that might impel job elimination. For each year, we therefore calculated the logged university budget based on appropriations from the Michigan congress. We also recorded whether the congress was under GOP control in each year. We proxied for broader economic conditions by including the state's unemployment rate, which - given the importance of manufacturing in Michigan-was a bellwether throughout this period. We also record the university's rankings by US News $E$ World Report, to capture any shocks related to change in the school's status. We count the number of years since a new president was chosen for the university, and the number of dean changes that occur across a job's sub-units, to capture any likely strategic shifts by the university administration. Finally, we record for each job description whether it was revised in any given year and its cumulative revisions over time. Table 2 presents the summary statistics for the variables used in our analyses; full bivariate correlations are reported in the online appendix.

[Table 2 about here.] 


\section{Results}

To test our hypotheses, we estimate Cox hazard models. Our models estimate whether technical interdependencies are related to a job's hazard of death. Our data consist of job-year observations. Because we have repeated individual observations of jobs, we cluster our standard errors at the level of the job to take into account the non-independence of those observations.

Table 3 presents the estimations. Model 1 shows the main effects of task overlap and task coordination, as well as fixed effects for the job's cohort (the year the job description was published) and the time period. The coefficient on task overlap is negative and significant, which supports hypothesis 1. Jobs whose constituent tasks overlap are less likely to die. A one-standard-deviation increase in task overlap reduced a job's hazard of death by about 10 percent. This technical interdependence is a non-trivial factor in a job's life chances. As seen for example in later models, it can almost offset the penalty associated with a job's being feminized (Baron \& Bielby 1985). The coefficient on task coordination is negative in model 1 but not significant. Once we include job size in model 2 and all subsequent models, it is significant. ${ }^{3}$ Its size is also comparable to that of task overlap: a one-standard-deviation increase in the number of coordinating words reduces a job's hazard of death by about 8 percent.

[Table 3 about here.]

Model 3 introduces the "job-level" controls. As expected, single-person jobs and jobs with high shares of female incumbents are more likely to die. Jobs that require a bachelor's degree or higher are less likely to die, but this effect is not significant. Mean tenure increases the hazard of job death, but this effect is substantively trivial. The effects of logged mean salary and FLSA status are not significant. On the other hand, full-time jobs and jobs that are embedded in hierarchical relationships are much more likely to survive.

Model 4 introduces fixed effects for the various job topics. Including these topics improves the model fit but leaves the estimated coefficients on our variables of interest substantively unchanged. Our results do not appear to be artifacts of the underlying task content of the jobs.

Model 5 tests hypothesis 3, that a job is more likely to die when jobs that are technically

\footnotetext{
${ }^{3}$ Coordination words are over-represented in very small and very large jobs. Among these high-coordination jobs, more are small than large. Because smaller jobs are more likely to die, if we do not control for job size then the effect of task coordination is swamped by the effect of job size.
} 
interdependent on it die. The count of the job's nearest neighbors that died in the previous year is positively and significantly associated with a greater hazard of job death. This lends support to hypothesis 3: interdependent groups of jobs die in groups. In addition to supporting hypothesis 3 , the results in model 5 also bolster support for hypothesis 1 . We say this because when a job's nearest neighbor dies, the focal job's overlap score decreases; when updated in the next year, its five nearest neighbors will have lower average overlap with it. We have theorized that lower task-overlap scores reflect jobs that are less technically interdependent with other jobs. However, because the death of task-overlapping jobs can also lower the score, our measure of task overlap might be confounded with other contagious processes. Because we can explicitly control for the death of neighboring jobs in model 5 and see that the coefficient on task overlap does not change, we have greater confidence that the latter reflects our theorized mechanism.

Model 6 introduces our measure of closed sub-units, to test hypothesis 4 . Its effect is positive but insignificant. By contrast, model 7 includes both this measure and interactions between it and our two measures of technical interdependence. In this model, we find that increasing the number of sub-units that are closed washes out the effect of task overlap on job survival. Simply put, being part of a cluster of related jobs does not seem to provide protection when clusters of jobs, rather than individual jobs, are being eliminated. However, the interaction between task coordination and sub-unit closure is not significant. Jobs that liaise with or coordinate across other jobs are no more or less likely to die when sub-units in which they are performed close. This pattern makes some intuitive sense, given that many liaison or coordinator jobs exist precisely to coordinate across organizational sub-units. Taken together, models 6 and 7 provide support for hypothesis 5 , but not for hypothesis 4 or 6 . We think that the non-support for hypothesis 4 in particular points to why it is important to theorize about jobs separately from the people who perform them. Closing a sub-unit virtually always implies laying off people; yet the same closure need not imply killing a job, which may continue to be performed elsewhere in the organization.

\section{Robustness checks}

In the analyses presented above, we made several methodological choices about how to construct our measure of task overlap. We examined whether our findings depend on the number of nearest neighbors that we use to define the score. The magnitude of its effect decreases as we increase 
the number of neighbors from five to ten, but this is consistent with adding noise to the measure. (Full results are available on request.) Even the noisiest measure remains negative and statistically significant.

All of our event-history models analyze jobs created after 1979. We do this because of leftcensoring and missing data on older jobs. We argue that our results on this sub-sample of the data can be generalized to the entire dataset, but we also recognize that there might be systematic differences in the types of jobs that were created before and after 1979. In particular, university staff and administrative positions have grown rapidly in recent decades, outpacing growth in all other types of jobs. If technical interdependencies were somehow to operate differently between these newer jobs than between older ones, generalizing from our sample to more jobs would be questionable.

To explore this issue, we took advantage of the job-topic fixed effects that we have calculated. We currently assign each job to one of ten substantive categories based on the language used in the description's duties and responsibilities. A full breakdown of the jobs by substantive category, as well as by creation before or after 1979 (and thus inclusion in our dataset) is given in the online appendix. Jobs that are more related to equipment, maintenance, and physical plant more generally are more likely to have been born before 1979 and thus omitted in our analyses. Meanwhile, jobs that are more related to programs and administration are more likely to have been included.

To see what effect these differential rates of inclusion have on our results, we reweighted the data based on job types. Specifically, for each of our ten substantive job-type categories, we calculated the probability that a job in that category would be omitted due to our sampling criterion. We then applied these probability weights to the observations in our sub-sample. Thus if a job category had twice as high an exclusion rate as the overall data then the included jobs in that category would receive a probability weight of 2 . We then re-estimated all of our main models on this weighted dataset. The results, which are available on request, show no substantive differences from our main results. We are therefore confident that our findings are not an artifact of our sampling scheme.

In our main analyses, we focused on the closure of sub-units as an example of larger strategic organizational choices that might affect job death. We also wanted to ensure that our main results are not confounded with other environmental changes that could affect the job structure. Model 8 of table 4 includes several such environmental controls, as described above in the construction of the 
control variables. Because these controls only vary by year, model 8 does not include time-period fixed effects. Their inclusion does not change our main results, and most are not significant. A perhaps surprising exception is GOP control of the state congress. The university has tended to eliminate more jobs when Republicans hold the legislature.

[Table 4 about here.]

In model 9, we include variables that might pick up internal strategic changes that could affect job survival. We control for the number of sub-units in which a job is found. A job's being performed in more sub-units reduces its chances of death, which makes intuitive sense; however, it does not alter the parameter estimate for the number of sub-units that are closed. Dean changes have no significant effect on job death.

Finally, model 10 explores how the effect of technical interdependence evolves over time. Job descriptions can be revised from year to year. Frequent revisions to a job's description could both affect its technical interdependencies and reflect uncertainty about what the job really should do, introducing spurious correlation between the technical-interdependence variables (which leverage the text of the descriptions) and job death. To test whether revisions to a job's description mediate the effect of technical interdependence, we controlled for whether a job's description was revised in the current year and the count of the number of changes over the job's history. Both effects are in the expected direction but neither is statistically significant, and the effect of our measures remain unchanged.

Overall, these robustness checks give us additional confidence in the pattern of results that we find. Jobs that are linked to other jobs by task overlap and task coordination are more likely to survive. Like prior studies, we find that "job-level" characteristics like feminization, job size and the job's status affect its life chances; but the structure of technical relationships between jobs within the organization plays a role in job survival and death even when such job-level features are taken into account.

\section{Discussion and conclusion}

The idea that jobs are linked together in structures is fundamental to theories of organizations as systems. Like those systems, job structures are not static. They change in response to environ- 
mental pressures, strategic shifts, and individual decision-making within the organization. Thus a central question in organization theory is how jobs structures change and evolve over time. While prior work has theorized about job structures, we have few direct investigations of such changes. Because we were long unable to observe job structures directly, our theories have tended to polarize into more macro- and micro-organizational camps (Barley \& Kunda 2001). Devising detailed yet generalizable ways to measure job structures holds the promise of returning our focus to the "meso"-level elements of the organization that have been so fruitful for theory development in the past, and could be again in the future.

The goal of our study is to return to a more meso-level perspective on organizations and organizational change. We do this by theorizing about, devising better measures of, and testing the implications of technical interdependence for the survival chances of specific jobs. Technical interdependence has long been a core concept within organizational research (Nelson \& Winter 1982), yet the data requirements to calculate interdependence among large numbers of jobs have long frustrated researchers. We operationalize technical interdependence in two ways: as task overlap and task coordination between jobs. We construct measures of each that are generalizable but that still let us control for the substantive task content of many diverse jobs. The advantage of this approach is that we can analyze job structures in far greater substantive detail than most macro-organizational work has, while obtaining more representative and generalizable results than case studies can provide.

In this study, we exploit an unusually large and detailed corpus of job descriptions and personnel records that covers tens of thousands of employees and more than 1,400 jobs in one of the United States's largest public universities. We use modern text-analysis techniques to compute measures of task overlap between each pair of jobs, leveraging those descriptions' detailed lists of tasks and responsibilities. We find that interdependence with other jobs, operationalized either as task overlap or as task coordination, protects a job. Thus at the dyadic level, interdependence unequivocally helps job survival. Yet when we shift our focus to the larger job structure, we find that such interdependence is a two-edged sword. Because interdependence ties a job's survival to its neighbors', the death of other jobs in the focal job's cluster increase its chances of death. We also find that the benefits of task overlap disappear when restructuring eliminates sub-units in which jobs are performed. Thus while technical interdependence can protect jobs in the course of 
day-to-day decision-making within organizations, larger strategic decisions can swamp its effects.

One intriguing contribution of this meso-level finding is its implications for macro-organizational behavior. We have argued that technical interdependence is "good" for a job, in the sense that it makes the job less likely to die. As we discussed above, such interdependence is not necessarily "good" for the organization in which the job is performed. If one were to compute task overlap and coordination measures for the job structures of many organizations, several research questions could follow. Organizations with highly interdependent routines that require careful coordination across multiple jobs are organizations that would have to make large strategic shifts or else lamely suffer in the face of environmental changes. Thus future research might ask whether organizations with slower-changing collections of jobs die at faster rates than organizations with more volatile collections of jobs. Similarly, we might hypothesize that organizations with more interdependent jobs tend to undertake fewer day-to-day job revisions, but more large strategic shifts, than organizations with less interdependent jobs. In effect, measures such as we have constructed here can be related not just to job change but to higher-level outcomes like organizational performance and survival.

These findings also have potential implications for individual-level outcomes. For example, our findings jibe with many theories of segmented labor markets (Piore 1973, Gordon, Edwards \& Reich 1982, Lang \& Dickens 1994), but go one step farther. Traditional labor-segmentation theory argued that employment relations were more unstable for individuals in peripheral jobs, but left unasked whether the jobs were also less stable. More recent work on "networked" and project-based labor markets that exist between and beyond firms (Bechky 2006, Barley \& Kunda 2004) implicitly presume that jobs and roles are subject to frequent change but, perhaps because of the starting premise that jobs can be identified with projects, have not investigated the correlates of such job turnover within particular labor markets. We think that the techniques that we have developed here suggest another way to identify the "precarity" of particular jobs (Kalleberg 2011), above and beyond categorical indicators like full-time/part-time or permanent/temporary. What is not clear from our data, but could be explored in future research, is whether the precarity of the job itself within an organization is correlated with the conditions and security of employment for the workers who hold the job. In organizations with more frequent redefinitions of jobs, it may also be possible to examine whether changes in task interdependence are themselves predictive of changes in job 
quality for the employee, as well as changes in the job's survival chances.

A similar extension of this research would be to explore the relationship between changes in a job structure and changes in the characteristics of the incumbents who fill positions within the structure. We can imagine for example that, where ascriptive differences divide a workforce, job descriptions might be revised over time to involve less task overlap and coordination between the two sets of jobs. Alternatively, we might hypothesize that increasing task overlap between jobs might reduce occupational segregation. More generally, this approach gives us a new window into how formal organizational structure and practice might change in response to demographic shifts, and vice versa.

Our study is methodologically novel as well. We have collected one of the largest longitudinal corpuses of formalized job descriptions and human-resource data to date. The nearly complete data on the various types of jobs in this internal labor market, ranging from janitorial staff to senior academic administrators, as well as the relatively long time-span, allow us to more cleanly isolate the effects of task overlap and coordination. We anticipate that future research could similarly combine large bodies of text about organizational processes and the modern tools to analyze them to help answer, and in some question to breathe new life into, classic questions of organizational behavior. Our rich data allow us to take into account heterogeneity among jobs with respect to their internal demographic composition, task content, rewards, and any sectoral effects of the time in which they were created. Furthermore, we control for macro-economic and strategic forces that are also likely to affect whether jobs survive or disappear.

That said, our study does have several important limitations. One has to do with how our measure of cosine similarity relates to the theoretical concept of task overlap. Jobs can overlap in tasks for many reasons. For example, two jobs may resemble one another because they perform the same work (functional); but they may also resemble one another because they contribute to the same product or process (divisional). Our measure of cosine similarity confounds such resemblances, but in practice their effects on job survival could differ. Functional overlap might make a job easier to eliminate because it offers opportunities for the organization to streamline operations and reduce costs, while divisional overlap might make a job harder to eliminate because the need for coordination is inherent to the division of labor. Our results suggest that, in this setting, the overall effect of task overlap is to increase job survival, but in an organization that is less 
functionally differentiated than a large research university the countervailing impact of functional overlap might be greater. Future research in different types of organizational settings, where these two types of overlap vary and can be better distinguished, would help address this limitation.

Second, we conduct our analysis within one organization, a large university system. This may make our results less generalizable. As we discussed above, we think that our findings are most relevant for larger, more established, and more hierarchical organizations. These are the types of organizations likely to have both a detailed division of labor and the personnel policies that would document and record specific practices across the resulting jobs. Ultimately we believe that this limitation can be both explored and overcome in future studies by collecting similar data for other types of organizations and for different time periods.

Indeed, by relaxing several of these scope conditions - by studying smaller firms where one job combines the tasks that would be done by several jobs in a larger firm, newer firms where job descriptions are more in flux, and "flatter" firms where jobs are less defined by their contribution to one part of a complex division of labor - it may be possible to theorize and explore changes in technical interdependence. In our setting, there is relatively little within-job change in technical interdependence over time. This limits our ability to study why and how a job could become more or less interdependent with other jobs, and the consequences of such within-job changes for survival and other outcomes. Thus applying our approach, for example to personnel and job-description data from other organizations, would be useful not only to test generalizability but also to test which scope conditions matter most for the effects we find.

A final limitation is that we cannot make strong causal claims with observational data such as these. We think that the most likely source of endogeneity in the present study is that some administrators could design some jobs to die. By this we mean that the administrator conceives of a job as temporary and/or intended for a very specific purpose, and therefore writes a job description that downplays or ignores any task overlap or coordination with other jobs. Even if this were true, the "peripherality" of the job description would lead to job death; but this would be owing to the prior design decision, which is a different mechanism than we have discussed here. Our data make this impossible to rule out, because we do not have information on the job-creation process.

Future research could try to address such endogeneity concerns in at least two ways. One is to gather more detailed information on the creation as well as the death of jobs. Another tactic 
would be to explore settings where the effects of task overlap and coordination themselves can be more cleanly identified. Such identification would require some sort of exogenous shock to the organization or jobs. A research setting like the one that Fernandez (2001) exploited to study technological change's effects on wage inequality is a useful prototype: in that case, tasks were assigned to different jobs but the firm and the workforce were held constant, and the outcome was cleanly mapped onto the theoretical constructs. Future studies on these lines could accomplish two things. First, they can clarify the effects of different types of interventions on job structures, which has obvious normative implications. Second, they can help clarify theory by describing the specific channels through which relationships between jobs mediate organizational change.

\section{References}

Abbott, Andrew. 1988. The System of Professions: An Essay on the Division of Labor. Chicago: University of Chicago Press.

Appelbaum, Eileen, Thomas Bailey, Peter Berg \& Arne Kalleberg. 2000. Manufacturing Advantage: Why High-performance Work Systems Pay Off. Ithaca: ILR Press.

Autor, David H., Frank Levy \& Richard J. Murnane. 2002. "Upstairs, Downstairs: Computers and Skills on Two Floors of a Large Bank." Industrial and Labor Relations Review 55(3):432-447.

Barker, James R. 1993. "Tightening the Iron Cage: Concertive Control in Self-Managing Teams." Administrative Science Quarterly 38:408-437.

Barley, Stephen R. 1986. "Technology as an Occasion for Structuring: Evidence from Observations of CT Scanners and the Social-Order of Radiology Departments." Administrative Science Quarterly 31(1):78108.

Barley, Stephen R. 1990. "The Alignment of Technology and Structure Through Roles and Networks." Administrative Science Quarterly 35(1):61-103.

Barley, Stephen R. \& Gideon Kunda. 2001. "Bringing Work Back In." Organization Science 12(1):76-95.

Barley, Stephen R. \& Gideon Kunda. 2004. Gurus, Hired Guns, and Warm Bodies: Itinerant Experts in a Knowledge Economy. Princeton, NJ: Princeton University Press.

Barnett, William P. \& Anne S. Miner. 1992. "Standing on the Shoulders of Others: Career Interdependence in Job Mobility." Administrative Science Quarterly 37(2):262-281.

Baron, James N. 2004. "Employing Identities in Organizational Ecology." Industrial and Corporate Change $13(1): 3-32$.

Baron, James N., Alison Davis-Blake \& William T. Bielby. 1986. "The Structure of Opportunity: How Promotion Ladders Vary within and among Organizations." Administrative Science Quarterly 31:248273.

Baron, James N. \& William T. Bielby. 1985. Organizational Barriers to Gender Equality: Sex Segregation of Jobs and Opportunities. In Gender and the Life Course, ed. Alice S. Rossi. New York: Aldine pp. 233-251.

Baron, James N. \& William T. Bielby. 1986. "The Proliferation of Job Titles in Organizations." Administrative Science Quarterly 31(4):561-586. 
Bechky, Beth A. 2003a. "Creating Shared Meaning Across Occupational Communities: The Transformation of Understanding on a Production Floor." Organization Science 14(3):312-330.

Bechky, Beth A. 2003b. "Object Lessons: Workplace Artifacts as Representations of Occupational Jurisdictions." American Journal of Sociology 109(3):720-752.

Bechky, Beth A. 2006. "Gaffers, Gofers, and Grips: Role-based Coordination in Temporary Organizations." Organization Science 17:3-21.

Blau, Peter M. 1963. The Dynamics of Bureaucracy. Chicago: University of Chicago Press.

Blei, David M., Andrew Y. Ng \& Michael I. Jordan. 2003. "Latent Dirichlet Allocation." Journal of Machine Learning Research 3:993-1022.

Boeker, Warren \& Robert Wiltbank. 2005. "New Venture Evolution and Managerial Capabilities." Organization Science 16(2):123-133.

Chamberlain, Neil W. 1948. The Union Challenge to Management Control. New York: Harper.

Cohen, Lisa E. 2012. Embedding Disruption: A Multi-level Model of Change in Organizational Job Structures. In Best Paper Proceedings. Academy of Management.

Cohen, Lisa E. 2013. "Assembling Jobs: A Model of How Tasks Are Bundled Into and Across Jobs." Organization Science 24(2):432-454.

Cohen, Lisa E. \& Joseph P. Broschak. 2014. "Whose Jobs Are These? The Impact of the Proportion of Female Managers on the Number of New Management Jobs Filled by Women versus Men." Administrative Science Quarterly 58(4):509-541.

Cohen, Michael \& Paul Bacdayan. 1994. "Organizational Routines Are Stored as Procedural Memory." Organization Science 5:554-568.

DiPrete, Thomas. 1989. The Bureaucratic Labor Market: The Case of the Federal Civil Service. New York: Plenum.

Doeringer, Peter \& Michael Piore. 1971. Internal Labor Markets and Manpower Analysis. Lexington, MA: Heath.

Fernandez, Roberto M. 2001. "Skill-Biased Technological Change and Wage Inequality: Evidence from a Plant Retooling." American Journal of Sociology 107(2):273-320.

Gordon, David M., Richard Edwards \& Michael Reich. 1982. Segmented Work, Divided Workers. London: Cambridge University Press.

Halpern, Sydney A. 1992. "Dynamics of Professional Control: Internal Coalitions and Crossprofessional Boundaries." American Journal of Sociology 97:994-1021.

Hannan, Michael T. \& John Freeman. 1984. "Structural Inertia and Organizational Change." American Sociological Review 49:149-164.

Hannan, Michael T., Lásló Pólos \& Glenn R. Carroll. 2003. "The Fog of Change: Opacity and Asperity in Organizations." Administrative Science Quarterly 48(3):399-432.

Hopkins, Daniel J. \& Gary King. 2010. "A Method of Automated Nonparametric Content Analysis for Social Science." American Journal of Political Science 54(1):229-247.

Huising, Ruthanne \& Susan S. Silbey. 2011. "Governing the Gap: Forging Safe Science through Relational Regulation." Regulation and Governance 5(1):14-42.

Kalleberg, Arne L. 2011. Good Jobs, Bad Jobs: The Rise of Polarized and Precarious Employment Systems in the United States. New York: Russell Sage Foundation.

Lang, Kevin \& William T. Dickens. 1994. Neoclassical and sociological perspectives on segmented labor markets. In Industries, Firms, and Jobs: Sociological and Economic Approaches, ed. George Farkas \& Paula England. New York: de Gruyter pp. 65-88. 
Lawrence, Paul D. \& Jay W. Lorsch. 1967. "Differentiation and Integration in Complex Organizations." Administrative Science Quarterly 12:1-47.

Leicht, Kevin T. \& Mary L. Fennell. 1997. "The changing organizational context of professional work." Annual Review of Sociology 23:215-231.

Meyer, John \& Brian Rowan. 1977. "Institutionalized Organizations: Formal Structures as Myth and Ceremony." American Journal of Sociology 83:340-363.

Miner, Anne S. 1987. "Idiosyncratic Jobs in Formalized Organizations." Administrative Science Quarterly 32:327-351.

Miner, Anne S. 1990. "Structural Evolution Through Idiosyncratic Jobs: The Potential for Unplanned Learning." Organization Science 1(2):195-210.

Miner, Anne S. 1991. "Organizational Evolution and the Social Ecology of Jobs." American Sociological Review 56:772-785.

Miner, Anne S. \& Suzanne E. Estler. 1985. "Accrual Mobility: Job Mobility in Higher Education through Responsibility Accrual." Journal of Higher Education 56(2):122-143.

Mintzberg, Henry. 1990. The Structuring of Organizations. New York: Prentice Hall.

Montgomery, David. 1979. Workers' Control in America. Cambridge: Cambridge University Press.

Morrill, Calvin. 1991. "Conflict Management, Honor, and Organizational Change." American Journal of Sociology 97:585-621.

Nelson, Richard \& Sidney Winter. 1982. An Evolutionary Theory of Economic Change. Cambridge, MA: Harvard University Press.

Noble, David F. 1984. Forces of Production: A Social History of Industrial Automation. New York: Knopf.

Osterman, Paul. 1987. "Choice among Alternative Internal Labor Markets." Industrial Relations 26:46-67.

Piore, Michael J. 1973. Notes for a Theory of Labor Market Stratification. In Labor Market Segmentation, ed. Richard C. Edwards, Michael Reich \& David M. Gordon. Lexington, MA: D.C. Heath and Company pp. $125-150$.

Reitzig, Markus \& Olav Sorenson. 2013. "Biases in the Selection Stage of Bottom-up Strategy Formulation." Strategic Management Journal 34(7):789-799.

Scott, W. Richard \& Gerald F. Davis. 2006. Organizations and Organizing: Rational, Natural and Open Systems. New York: Pearson.

Singer, Judith D. \& John B. Willett. 2003. Applied longitudinal data analysis: Modeling change and event occurrence. New York: Oxford University Press.

Smith, Vicki. 1990. Managing in the Corporate Interest. Berkeley, CA: University of California Press.

Sørensen, Jesper B. 2002. "Strong Corporate Cultures and the Reliability of Organizational Performance." Administrative Science Quarterly 47:70-91.

Strang, David \& James N. Baron. 1990. "Categorical Imperatives: The Structure of Job Titles in California State Agencies." American Sociological Review 55:479-495.

Thompson, James D. 1967. Organizations in Action: Social Science Bases of Administrative Theory. New York: McGraw-Hill.

Trist, E. L. \& K. W. Bamforth. 1951. "Some Social and Psychological Consequences of the Longwall Method of Coal Getting." Human Relations 4:3-38.

Weber, Max. 1968. Bureaucracy. In Economy and Society: An Outline of Interpretive Sociology, ed. Guenther Roth \& Claus Wittich. Vol. 3 Bedminster Press pp. 956-969.

Woodward, Joan. 1984. Management and Technology. In Organization Theory: Selected Readings, ed. D. S. Pugh. second ed. New York: Penguin pp. 52-66. 
Table 1: Sample of the components of a job's task overlap score. The measure described in the text sums the cosine similarity of the five jobs with the highest similarity to the focal job. Here we show sample jobs from four points in the task-overlap distribution, as well as the five most overlapping jobs.

\begin{tabular}{|c|c|c|c|}
\hline $\begin{array}{l}\text { Locksmith } \\
\text { (10th \%ile) }\end{array}$ & & $\begin{array}{l}\text { Supervisor, Cyclotron Facilities } \\
\text { (25th \%ile) }\end{array}$ & \\
\hline Supervisor, Univ. Key Systems & 0.223 & Senior Cyclotron Operator & 0.584 \\
\hline Coordinator, Access Control & 0.172 & Cyclotron Operator & 0.440 \\
\hline Supervior, Security/Access Control & 0.164 & Clinical Physicist & 0.145 \\
\hline Maintenance Mechanic II & 0.163 & Instrument Engineer, Power Plant & 0.140 \\
\hline Heavy Equipment Mechanic & 0.157 & Manager of Facilities, Univ. Unions & 0.140 \\
\hline Task Similarity Score & 0.879 & Task Similarity Score & 1.449 \\
\hline $\begin{array}{c}\text { Director of Annual Giving Prograr } \\
\text { (75th \%ile) }\end{array}$ & & $\begin{array}{c}\text { Physical Therapy Clinical Specialist } \\
\text { (90th \%ile) }\end{array}$ & \\
\hline Development Officer II & 0.370 & Occupational Therapy Clinical Specialist & 0.584 \\
\hline Sr. Assoc. Director, Annual Programs & 0.358 & Physical Therapist II & 0.489 \\
\hline Director, College Relations/COE & 0.354 & Physical Therapist I & 0.437 \\
\hline Associate Major Gift Officer & 0.351 & Physical Therapy Assistant II & 0.413 \\
\hline Assistant Major Gift Officer & 0.316 & Wound Care Specialist & 0.393 \\
\hline Task Similarity Score & 1.749 & Task Similarity Score & 2.316 \\
\hline
\end{tabular}


Table 2: Summary statistics

\begin{tabular}{llccccc}
\hline \hline Variable & Name in tables & Count & Mean & S.D. & Min & Max \\
\hline Job dies in current year & Death & 15604 & 0.04 & 0.20 & 0 & 1 \\
Task overlap & Task Overlap & 15604 & 1.73 & 0.63 & 0.39 & 4.61 \\
Task coordination & Task Coord. & 15604 & 1.52 & 1.68 & 0 & 11 \\
Number of neighbors died & Neighbor Death & 15604 & 0.22 & 0.51 & 0 & 5 \\
Number of sub-units & \# Units & 15604 & 1.97 & 3.51 & 1 & 50 \\
Number of sub-units closed & \# Units Closed & 15604 & 0.40 & 0.65 & 0 & 9 \\
Number of incumbents & Size & 15604 & 7.06 & 18.26 & 1 & 286 \\
Only one incumbent & Singleton & 15604 & 0.49 & 0.50 & 0 & 1 \\
More than 80\% female & Feminized & 15604 & 0.47 & 0.50 & 0 & 1 \\
Log of mean salary & Log Salary & 15604 & 11.01 & 0.51 & 9.84 & 12.85 \\
Mean tenure & Mean Tenure & 15604 & 9.24 & 5.86 & 1 & 59 \\
Bachelors required & Bachelors & 15604 & 0.25 & 0.43 & 0 & 1 \\
FLSA Non-exempt & FLSA Non-exemp & 15604 & 0.22 & 0.41 & 0 & 1 \\
Hierarchically embedded & Hier. Rel. & 15604 & 0.51 & 0.50 & 0 & 1 \\
Mean full-time equivalents & Full-time & 15604 & 0.99 & 0.04 & 0 & 1 \\
Log of university budget & Univ. Budget & 15604 & 12.85 & 0.06 & 12.55 & 12.92 \\
USN\&WR rank & USN\&WR Rank & 15604 & 19.70 & 6.86 & 7 & 25 \\
GOP state congress & GOP Congress & 15604 & 0.48 & 0.50 & 0 & 1 \\
New-president tenure & New President & 15604 & 3.21 & 2.42 & 0 & 8 \\
State unemployment rate & Unemp. Rate & 15604 & 6.98 & 2.65 & 3.66 & 15.37 \\
Job description revised & Desc. Revision & 15604 & 0.03 & 0.17 & 0 & 1 \\
Cumulative revisions & Cum. Revisions & 15604 & 0.28 & 0.53 & 0 & 3 \\
Sub-units with dean changes & Dean Changes & 15604 & 0.08 & 0.34 & 0 & 5 \\
\hline \hline
\end{tabular}


Table 3: Cox Proportional Hazard Models of Job Death

\begin{tabular}{|c|c|c|c|c|c|c|c|}
\hline & (1) & $(2)$ & (3) & (4) & (5) & (6) & (7) \\
\hline \multirow[t]{2}{*}{ Task Overlap } & $-0.20^{* *}$ & $-0.18^{* *}$ & $-0.14^{*}$ & $-0.15^{+}$ & $-0.16^{*}$ & $-0.16^{*}$ & $-0.24^{* *}$ \\
\hline & $(0.07)$ & $(0.07)$ & $(0.07)$ & $(0.08)$ & $(0.08)$ & $(0.08)$ & $(0.09)$ \\
\hline \multirow[t]{2}{*}{ Task Coord. } & -0.01 & $-0.05^{*}$ & $-0.07^{* *}$ & $-0.07^{* *}$ & $-0.07^{* *}$ & $-0.07^{* *}$ & $-0.06^{*}$ \\
\hline & $(0.02)$ & $(0.03)$ & $(0.03)$ & $(0.03)$ & $(0.03)$ & $(0.03)$ & $(0.03)$ \\
\hline \multirow[t]{2}{*}{ Size } & & $-0.22^{* *}$ & $-0.07^{+}$ & $-0.07^{+}$ & $-0.07^{+}$ & $-0.07^{+}$ & $-0.07^{+}$ \\
\hline & & $(0.07)$ & $(0.04)$ & $(0.04)$ & $(0.04)$ & $(0.04)$ & $(0.04)$ \\
\hline \multirow[t]{2}{*}{ Singleton } & & & $1.24^{* *}$ & $1.26^{* *}$ & $1.27^{* *}$ & $1.28^{* *}$ & $1.28^{* *}$ \\
\hline & & & $(0.21)$ & $(0.21)$ & $(0.20)$ & $(0.20)$ & $(0.20)$ \\
\hline \multirow[t]{2}{*}{ Feminized } & & & $0.23^{* *}$ & $0.15^{+}$ & $0.15^{+}$ & $0.15^{+}$ & $0.15^{+}$ \\
\hline & & & $(0.08)$ & $(0.09)$ & $(0.09)$ & $(0.09)$ & $(0.09)$ \\
\hline \multirow[t]{2}{*}{ Log Salary } & & & -0.04 & -0.16 & -0.18 & -0.19 & -0.18 \\
\hline & & & $(0.11)$ & $(0.12)$ & $(0.12)$ & $(0.12)$ & $(0.12)$ \\
\hline \multirow[t]{2}{*}{ Mean Tenure } & & & $0.02^{* *}$ & $0.02^{* *}$ & $0.02^{* *}$ & $0.02^{* *}$ & $0.02^{* *}$ \\
\hline & & & $(0.01)$ & $(0.01)$ & $(0.01)$ & $(0.01)$ & $(0.01)$ \\
\hline \multirow[t]{2}{*}{ Bachelors } & & & -0.09 & -0.14 & -0.13 & -0.14 & -0.14 \\
\hline & & & $(0.12)$ & $(0.12)$ & $(0.12)$ & $(0.12)$ & $(0.12)$ \\
\hline \multirow[t]{2}{*}{ FLSA Non-Exempt } & & & 0.08 & 0.23 & 0.24 & 0.24 & 0.25 \\
\hline & & & $(0.14)$ & $(0.15)$ & $(0.15)$ & $(0.15)$ & $(0.15)$ \\
\hline \multirow[t]{2}{*}{ Hier. Rel. } & & & $-0.35^{* *}$ & $-0.33^{* *}$ & $-0.30^{* *}$ & $-0.30^{* *}$ & $-0.30^{* *}$ \\
\hline & & & $(0.11)$ & $(0.11)$ & $(0.11)$ & $(0.11)$ & $(0.11)$ \\
\hline \multirow[t]{2}{*}{ Full-time } & & & $-1.01^{+}$ & $-1.28^{*}$ & $-1.30^{*}$ & $-1.32^{*}$ & $-1.30^{*}$ \\
\hline & & & $(0.58)$ & $(0.57)$ & $(0.57)$ & $(0.57)$ & $(0.57)$ \\
\hline \multirow[t]{2}{*}{ Neighbor Death } & & & & & $0.43^{* *}$ & $0.43^{* *}$ & $0.43^{* *}$ \\
\hline & & & & & $(0.06)$ & $(0.06)$ & $(0.06)$ \\
\hline \multirow[t]{2}{*}{ \# Units Closed } & & & & & & 0.09 & $-0.52^{*}$ \\
\hline & & & & & & $(0.09)$ & $(0.26)$ \\
\hline \multirow[t]{2}{*}{ \# Units Closed $\times$ Task Overlap } & & & & & & & $0.36^{*}$ \\
\hline & & & & & & & $(0.14)$ \\
\hline \multirow[t]{2}{*}{ \# Units Closed $\times$ Task Coord. } & & & & & & & 0.01 \\
\hline & & & & & & & $(0.06)$ \\
\hline Cohort F.E.s & Y & $\mathrm{Y}$ & $\mathrm{Y}$ & $\mathrm{Y}$ & $\mathrm{Y}$ & $\mathrm{Y}$ & $\mathrm{Y}$ \\
\hline Time-period F.E.s & $\mathrm{Y}$ & $\mathrm{Y}$ & $\mathrm{Y}$ & $\mathrm{Y}$ & $\mathrm{Y}$ & $\mathrm{Y}$ & Y \\
\hline Job-topic F.E.s & $\mathrm{N}$ & $\mathrm{N}$ & $\mathrm{N}$ & $\mathrm{Y}$ & $\mathrm{Y}$ & $\mathrm{Y}$ & $\mathrm{Y}$ \\
\hline Jobs & 1405 & 1405 & 1405 & 1405 & 1405 & 1405 & 1405 \\
\hline Job Deaths & 595 & 595 & 595 & 595 & 595 & 595 & 595 \\
\hline Job-years at Risk & 15604 & 15604 & 15604 & 15604 & 15604 & 15604 & 15604 \\
\hline Model d.f. & 10 & 11 & 19 & 28 & 29 & 30 & 32 \\
\hline Log-likelihood & -3942.04 & -3826.69 & -3763.29 & -3748.50 & -3723.50 & -3723.10 & -3720.53 \\
\hline
\end{tabular}

Robust standard errors (in parentheses) are clustered by job.

${ }^{+} p<.10,{ }^{*} p<.05,{ }^{* *} p<.01$ 
Table 4: Robustness Checks: Cox Proportional Hazard Models of Job Death

\begin{tabular}{|c|c|c|c|}
\hline & (8) & $(9)$ & $(10)$ \\
\hline \multirow[t]{2}{*}{ Task Overlap } & $-0.16^{*}$ & $-0.25^{* *}$ & $-0.25^{* *}$ \\
\hline & $(0.08)$ & $(0.09)$ & $(0.09)$ \\
\hline \multirow[t]{2}{*}{ Task Coord. } & $-0.07^{*}$ & $-0.06^{*}$ & $-0.07^{*}$ \\
\hline & $(0.03)$ & $(0.03)$ & $(0.03)$ \\
\hline \multirow[t]{2}{*}{ Neighbor Death } & $0.39^{* *}$ & $0.42^{* *}$ & $0.44^{* *}$ \\
\hline & $(0.06)$ & $(0.06)$ & $(0.06)$ \\
\hline \multirow[t]{2}{*}{ Size } & $-0.06^{+}$ & -0.03 & $-0.07^{+}$ \\
\hline & $(0.04)$ & $(0.03)$ & $(0.04)$ \\
\hline \multirow[t]{2}{*}{ Singleton } & $1.25^{* *}$ & $1.11^{* *}$ & $1.28^{* *}$ \\
\hline & $(0.20)$ & $(0.17)$ & $(0.20)$ \\
\hline \multirow[t]{2}{*}{ Feminized } & 0.14 & $0.16^{+}$ & $0.16^{+}$ \\
\hline & $(0.09)$ & $(0.09)$ & $(0.09)$ \\
\hline \multirow[t]{2}{*}{ Log Salary } & -0.16 & -0.18 & -0.19 \\
\hline & $(0.12)$ & $(0.12)$ & $(0.12)$ \\
\hline \multirow{2}{*}{ Mean Tenure } & $0.02^{* *}$ & $0.02^{* *}$ & $0.02^{* *}$ \\
\hline & $(0.01)$ & $(0.01)$ & $(0.01)$ \\
\hline \multirow[t]{2}{*}{ Bachelors } & -0.16 & -0.14 & -0.14 \\
\hline & $(0.12)$ & $(0.12)$ & $(0.12)$ \\
\hline \multirow[t]{2}{*}{ FLSA Non-Exempt } & 0.24 & 0.20 & 0.22 \\
\hline & $(0.15)$ & $(0.15)$ & $(0.15)$ \\
\hline \multirow[t]{2}{*}{ Hier. Rel. } & $-0.31^{* *}$ & $-0.29^{* *}$ & $-0.31^{* *}$ \\
\hline & $(0.11)$ & $(0.11)$ & $(0.11)$ \\
\hline \multirow{2}{*}{ Full-time } & $-1.11^{+}$ & $-1.17^{+}$ & $-1.32^{*}$ \\
\hline & $(0.57)$ & $(0.61)$ & $(0.57)$ \\
\hline \multirow[t]{2}{*}{ Univ. Budget } & $-0.00^{+}$ & & \\
\hline & $(0.00)$ & & \\
\hline \multirow[t]{2}{*}{ USNESWR Rank } & -0.01 & & \\
\hline & $(0.01)$ & & \\
\hline \multirow[t]{2}{*}{ GOP Congress } & $0.36^{*}$ & & \\
\hline & $(0.17)$ & & \\
\hline \multirow[t]{2}{*}{ New President } & -0.01 & & \\
\hline & $(0.03)$ & & \\
\hline \multirow[t]{2}{*}{ Unemp. Rate } & -0.04 & & \\
\hline & $(0.04)$ & & \\
\hline \multirow[t]{2}{*}{ \# Units Closed } & & $-0.58^{*}$ & $-0.53^{*}$ \\
\hline & & $(0.29)$ & $(0.26)$ \\
\hline \multirow[t]{2}{*}{ \# Units Closed $\times$ Task Overlap } & & $0.45^{* *}$ & $0.36^{*}$ \\
\hline & & $(0.16)$ & $(0.14)$ \\
\hline \# Units Closed $\times$ Task Coord. & & 0.00 & 0.01 \\
\hline & & $(0.07)$ & $(0.06)$ \\
\hline \# Units & & $-0.74^{* *}$ & \\
\hline & & $(0.13)$ & \\
\hline Dean Changes & & -0.14 & \\
\hline & & $(0.31)$ & \\
\hline Desc. Revision & & & $-0.81^{*}$ \\
\hline & & & $(0.33)$ \\
\hline Cum. Revisions & & & 0.10 \\
\hline & & & $(0.09)$ \\
\hline Cohort F.E.s & Y & $\mathrm{Y}$ & $\mathrm{Y}$ \\
\hline Time-period F.E.s & $\mathrm{N}$ & $\mathrm{Y}$ & $\mathrm{Y}$ \\
\hline Job-topic F.E.s & $\mathrm{Y}$ & $\mathrm{Y}$ & $\mathrm{Y}$ \\
\hline Jobs & 1405 & 1405 & 1405 \\
\hline Job Deaths & 595 & 595 & 595 \\
\hline Job-years at Risk & 15604 & 15604 & 15604 \\
\hline Model d.f. & 26 & 34 & 34 \\
\hline Log-likelihood & -3726.09 & -3701.51 & -3715.80 \\
\hline
\end{tabular}




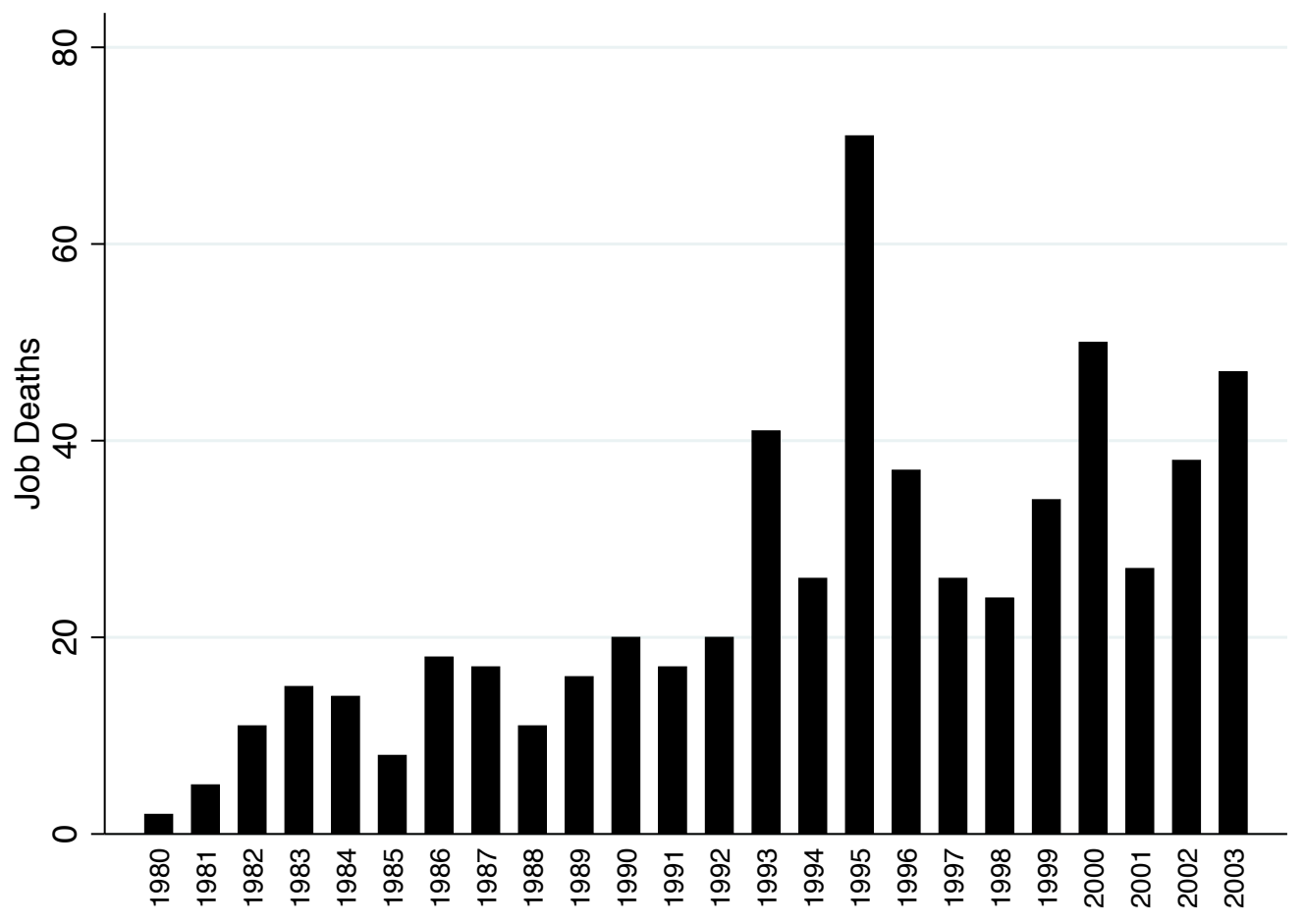

Figure 1: Job deaths at the University of Michigan, by year. A job is coded as having died in year $t$ when it is observed to have no incumbents after $t$. Job deaths do not include renamings, as described in the text. 